\title{
Studying the impact factors influencing variable-capacity heat pump energy performance through simulation
}

\author{
Solange Prud'homme ${ }^{1}$, Stéphanie Breton ${ }^{1}$, Justin Tamasauskas ${ }^{1}$, Alex Lachance ${ }^{1}$, and Martin Kegel ${ }^{1}$
}

${ }^{1}$ CanmetENERGY/Natural Resources Canada, Varennes, QC, Canada

\begin{abstract}
Cold-climate variable-capacity air-to-air heat pumps (VCHPs) have the potential to significantly reduce energy use in the Canadian residential sector. However, optimizing their integration in the Canadian climate can be a challenge, with efficiency and operating behaviour heavily dependent on ambient conditions, building thermal loads, modulating capability and the units' individual performance characteristics. Better understanding how these factors influence energy performance can lead to improved system selection, and ensure that high efficiency space heating systems contribute towards meeting Canada's emission reduction targets. This study outlines three major factors - individual performance characteristics (cold climate capacity, part load performance), modulation ratio and sizing - related to VCHP selection, and examines their relative impact on annual energy use and operating behaviour using a simulation-based approach.
\end{abstract}

\section{Introduction}

The building sector accounts for nearly $17 \%$ of Canada's greenhouse gas emissions [1], with space heating representing close to $63 \%$ of the energy end use. To reduce this energy end use, a Market Transformation Roadmap has been developed identifying initiatives to increase the adoption of high performing systems in the Canadian residential and commercial building sector. Heat pumps are identified in the Roadmap as one of key space heating technologies having a Seasonal performance $>100 \%$, however, their integration in Canadian buildings is hindered due to uncertain seasonal performance and ability of the system to meet desired heating loads.

Air-source (air-to-air) heat pumps are the most common type of heat pump integration in Canadian residential buildings. However, large capacity degradations at colder temperatures associated with traditional air-source units can reduce energy savings in Canada. Recently, the market has seen the introduction of cold-climate variable-capacity heat pumps (VCHPs).

VCHPs can efficiently meet space heating loads at low outdoor air temperatures by using larger outdoor heat exchanger coils, variable-speed fans and inverterdriven compressors, while still efficiently modulating during warmer conditions [2]. While VCHPs have strong potential in the cold Canadian climate, appropriate system selection and sizing are essential. VCHP performance varies between units based on the individual performance characteristics of the heat pump (part-load performance and cold-climate capacity), and factors such as the modulation ratio of the heat pump and system sizing. Previous studies have underlined the importance of appropriately capturing the part load performance of variable capacity systems [3]; [4], and the impact that this can have on sizing, operations, and system control [5]. However, the cold Canadian climate necessitates a systematic evaluation on the influence of these three factors on the annual energy performance and operating behaviour of the heat pump.

This paper applies a simulation-based approach, driven by a quasi-transient heat pump model, to explore the energy performance implications of these factors for two different VCHP units integrated in a single-family home in Montreal, Canada. First, detailed information is given about key performance characteristics of VCHPs and the factors investigated in this study. The simulation methodology used to examine these factors is then discussed, starting with the presentation of a detailed 1990s single-family housing model in Montreal. Then, the data-driven heat pump model used is discussed, along with a description of the two selected VCHP units compared in this study. Developed building and heat pump models are then combined to explore the impact of VCHP sizing and modulation ratio on the annual performance of each system. Results are used to derive insights to better integrate VCHPs in Canadian residential buildings.

\section{VCHP Performance Characteristics}

Compared to traditional single-stage heat pumps, VCHPs offer greater flexibility to adapt to building loads across a wide range of ambient conditions. While this allows for improved energy savings and thermal comfort within the building [2], it also complicates sizing and selection, as a greater number of performance characteristics must be considered to ensure optimal integration.

VCHPs are typically defined by several individual operating characteristics. One of the most important of these aspects is the capacity curve, which defines the maximum (heating or cooling) capacity of the unit at a given outdoor temperature. This characteristic has important implications for overall system energy use, as insufficient capacity at colder temperatures may require the use of auxiliary heating systems. Figure 1 compares the capacity curve at maximum compressor frequency for two different inverter-driven heat pump units [6]. While both units make use of variable-capacity technology, VCHP 1 can operate down to lower outdoor air temperatures and maintains a far more significant portion of its heating capacity across its range of operating conditions. This suggests that VCHP 1 would be able to meet a more significant portion of heating 
loads vs. VCHP 2, for the same rated unit size. However, the magnitude of these energy savings in an actual building is highly dependent on other factors, including unit sizing and local climate.

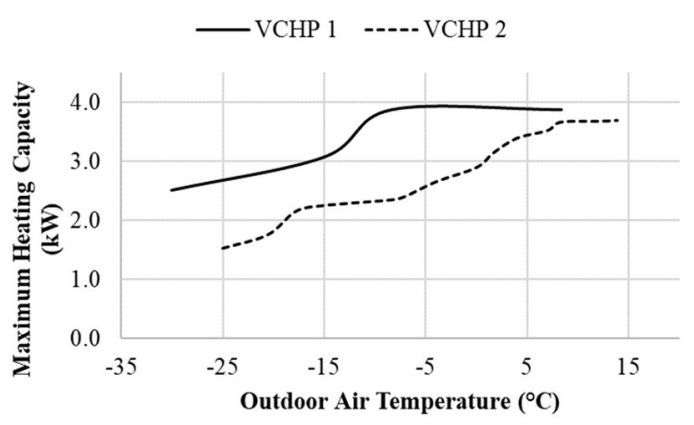

Figure 1. Heating capacity curves for two generic VCHPs.

VCHP performance is also highly dependent on the efficiency of the unit, both under full-load and part-load conditions. Heat pump efficiency is often specified as the coefficient of performance (COP, ratio of thermal energy delivered to electrical power input) at rated/maximum compressor frequency. However, heat pumps rarely operate at full load especially under warmer ambient temperature conditions. As such, rated COPs do not provide a full depiction of system performance in an actual installation, making it critical to also examine part-load performance. Figure 2 illustrates the variation in part-load factor (PLF, ratio of actual COP to COP at full load) as a function of the partload ratio (PLR, ratio of actual system capacity to maximum capacity) at a given outdoor air temperature [6]. It is interesting to note the strong difference in partload performance between the two units: VCHP 1 shows a noticeable and sustained increase in steady-state efficiency at lower PLR, down to a minimum PLR of $35 \%$. In comparison, VCHP 2 has steady-state efficiencies that decrease below PLR of $45 \%$, with a lower minimum PLR of $18 \%$.

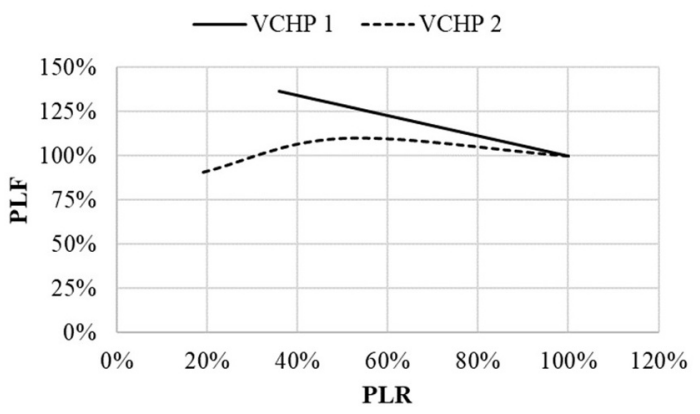

Figure 2. Part-load performance for two generic VCHPs.

As can be seen in Figure 2, part-load performance is also related to the ability of the heat pump to modulate its capacity. This property can be characterized by the modulation ratio of the heat pump, defined as the ratio of its minimum to maximum compressor frequencies. It indicates how well-suited the heat pump is to meet building loads at both very cold and milder conditions without cycling on/off. It is important to note that, since the modulation ratio is based on frequency, it does not translate directly to the PLR (which is based on capacity).

Finally, heat pump sizing relative to building conditioning loads also impacts system performance. Sizing naturally impacts how much of the load will be covered by the heat pump, but also influences how frequently the unit may cycle at milder conditions. NRCan's Air-Source Heat Pump Sizing and Selection Guide [5] suggests matching heat pump capacity to building load at $17^{\circ} \mathrm{F}\left(-8.3^{\circ} \mathrm{C}\right)$ for heating-dominated applications. However, while general guidelines are useful as a starting point, it is unclear how the other factors defined above impact the applicability of this sizing approach.

While it is clear that a number of factors may influence VCHP performance, few studies have systematically examined these impacts in Canadian buildings. The remainder of this paper will examine, for two different heat pump units (each with different individual capacity and part-load performance), how these factors influence performance:

- Modulation Ratio: Examining minimum ratios of $30 \%, 50 \%$, and $80 \%$.

- Sizing: Using the building load at $17^{\circ} \mathrm{F}\left(-8.3^{\circ} \mathrm{C}\right)$ as an initial target, and investigating four sizing factors: $0.5,1,1.5$, and 2 .

\section{Modelling Methodology}

Assessing the impact of each performance characteristic requires an appropriate simulation framework. TRNSYS v.18 [7] is selected as the main simulation platform due to its large library of components and its flexibility in modelling complex and custom HVAC systems.

\subsection{Housing Model}

Each heat pump case was integrated into a typical single-family Canadian home in Montreal, QC. Building geometry was defined based on the Canadian Centre for Housing Technology (CCHT) test homes located in Ottawa, ON [8], and consists of two above-ground floors and a finished basement, with a total heated floor area of $284 \mathrm{~m}^{2}$. The envelope of the home was then modified to represent typical 1990 s construction using location-specific information extracted from the Canadian Single-Detached and Double/Row Housing Database (CSDDRD) [9]. A summary of key housing parameters for Montreal is provided in Table 1.

Table 1. Montreal housing model parameters.

\begin{tabular}{cccc}
\hline $\begin{array}{c}\text { Wall RSI } \\
\left(\mathbf{m}^{\mathbf{2}} \cdot \mathbf{C} / \mathbf{W}\right)\end{array}$ & $\begin{array}{c}\text { Roof RSI } \\
\left(\mathbf{m}^{\mathbf{2}} \cdot \mathbf{C} / \mathbf{W}\right)\end{array}$ & $\begin{array}{c}\text { Window } \mathbf{~} \\
\text { Value } \\
\left(\mathbf{W} / \mathbf{m}^{\mathbf{2}}\right)\end{array}$ & $\begin{array}{c}\text { Infiltration } \\
(\mathbf{A C H})\end{array}$ \\
\hline 3.1 & 4.8 & 2.9 & 4.3 \\
\hline
\end{tabular}

The housing model was developed in TRNSYS v.18 using the Type 56 component. Profiles for lighting and receptacles are occupant-driven and were based on representative Canadian profiles developed for IEA ECBCS Annex 42 [10]. 
To provide a point of reference for heat pump integration, a base case mechanical system is also defined. The CSDDRD indicates that the majority of homes in the Montreal region are electrically heated. As such, the base case mechanical system is defined as consisting of electric baseboards on all three levels of the home.

\subsection{Heat Pump Integration and Modelling}

\subsubsection{Integration and Sizing}

Since the base case home is heated using electric baseboards, it is assumed that no central ducting network exists. As such, a ductless single-split (one indoor unit, one outdoor unit) integration is proposed, as is common in the Canadian market [11]. The single indoor head is assumed to be located in the stairwell between the first and second floors, with the basement heated only via electric baseboards as in the base case.

Since air-source heat pumps naturally experience a degradation in heating capacity at colder outdoor conditions, auxiliary heating systems are required. For the selected case study, this auxiliary system consists of electric baseboards on each level of the home. System control is selected to prioritize heat pump operation. The heat pump operates to maintain a set point temperature of $21^{\circ} \mathrm{C}$ on the second floor, while the auxiliary electric baseboards activate to supplement heat pump operations when the indoor air temperature in the zone drops below $20^{\circ} \mathrm{C}$.

Initial heat pump sizing is based on matching heat pump capacity at maximum frequency to the building load at $17^{\circ} \mathrm{F}\left(-8.3^{\circ} \mathrm{C}\right)$. This study also examines the impact of over- and undersizing by applying other sizing factors, as outlined above. The required heat pump capacity at $17^{\circ} \mathrm{F}\left(-8.3^{\circ} \mathrm{C}\right)$ for each Sizing Option is summarized below in Table 2. While sizing guidelines do not specify if selection should be done based on maximum or rated VCHP capacity, a sensitivity analysis by Prud'homme et al. [12] revealed that sizing for maximum frequency resulted in more efficient operation for this specific integration (Montreal, 1990s housing).

Table 2. Heating load and unit size for each option.

\begin{tabular}{ccc}
\hline $\begin{array}{c}\text { Sizing } \\
\text { option }\end{array}$ & $\begin{array}{c}\text { Resulting } \\
\text { heating load } \\
\text { (kW) }\end{array}$ & $\begin{array}{c}\text { Unit size } \\
\text { selected } \\
\text { (ton) }\end{array}$ \\
\hline 1 & 3.2 & 1 \\
2 & 6.5 & 2 \\
3 & 9.7 & 3 \\
4 & 13.0 & 4 \\
\hline
\end{tabular}

\subsubsection{Heat Pump Modelling}

This study uses an enhanced VCHP component model developed in TRNSYS (Type 3256) to better estimate the performance and the energy consumption of such units [13]; [14]. Type 3256 is based on extensive experimental testing of VCHP systems, and integrates key features including performance variation with compressor frequency, and short-term behaviour including defrost and start-up:
Defrost Behaviour: Defrost is activated based on ambient temperature, and compressor run time since last defrost. Defrost mode also includes cooling supplied to the space, which is determined using either experimental test data, or, in cases where this is not available, estimated using manufacturer supplied cooling performance data at low ambient temperatures. A time constant approach is used to account for the lag in reaching steady state heating capacity after completing a defrost process.

Start-up Behaviour: Upon start-up, heating capacity ramps to steady state based on a time constant approach. Time constants are derived from experimental testing of heat pumps at the CanmetENERGY in Varennes facility. Start-up behaviour also includes controls which ramp up compressor frequency to maximum speed upon start-up, based on testing observations.

Other: Standby losses are also taken into account during the simulations, assuming $20 \mathrm{~W} /$ ton rated cooling capacity [15].

Type 3256 is a data-driven model that requires an appropriate map of normalized capacity and power as a function of indoor and outdoor temperatures, and compressor frequency. Identifying appropriate performance data is therefore a crucial element of the simulation methodology. For this study, performance data was derived from:

- Unit 1: Detailed experimental test data of a ductless mini-split unit [14];

- Unit 2: Data for a commercially-available unit accessible via the Northeast Energy Efficiency Partnerships Cold Climate Heat Pump Database [6].

Note that Unit 1 was selected because detailed test data was available for this VCHP model. Unit 2 was selected because it had different characteristics from Unit 1 in terms of cold climate capacity maintenance and part load performance. A summary of COPs at maximum frequency for different outdoor air temperatures is provided for both units in Table 3. This table also provides the rated heating capacity of each unit for a one ton sizing, which means that this capacity will be two, three or four times greater for the Sizing Options 2, 3 or 4, respectively.

Table 3. COP at full load at different outdoor temperatures.

\begin{tabular}{ccc}
\hline $\begin{array}{c}\text { ODB } \\
\left({ }^{\circ} \mathbf{C}\right)\end{array}$ & $\begin{array}{c}\text { Unit 1 } \\
\text { Max COP }\end{array}$ & $\begin{array}{c}\text { Unit 2 } \\
\text { Max COP }\end{array}$ \\
\hline-25 & 1.7 & - \\
-20 & 1.7 & 1.9 \\
-15 & 1.7 & 2.3 \\
-8.3 & 1.7 & 2.7 \\
8.3 & 1.9 & 3.2 \\
\hline $\begin{array}{c}\text { Rated heating } \\
\text { capacity* } \\
\text { (kW) }\end{array}$ & 4.0 & 4.1 \\
\hline *At AHRI Rating Conditions &
\end{tabular}

Since normalized data is used in the performance map, heat pump performance can easily be scaled using a multiplication factor, providing flexibility in the analysis process, while ensuring other performance characteristics remain the same between simulated 
options. Figure 3 compares the normalized capacity used in the simulations for both units at minimum, rated, and maximum compressor frequencies.

Unit 1 has a much stronger ability to maintain its rated capacity at colder operating temperatures. While Unit 2 uses similar technology, the unit has more difficulty maintaining its heating capacity at low outdoor temperatures, and also has a higher cut-off operating temperature $\left(-20^{\circ} \mathrm{C}\right.$ vs $\left.-25^{\circ} \mathrm{C}\right)$.

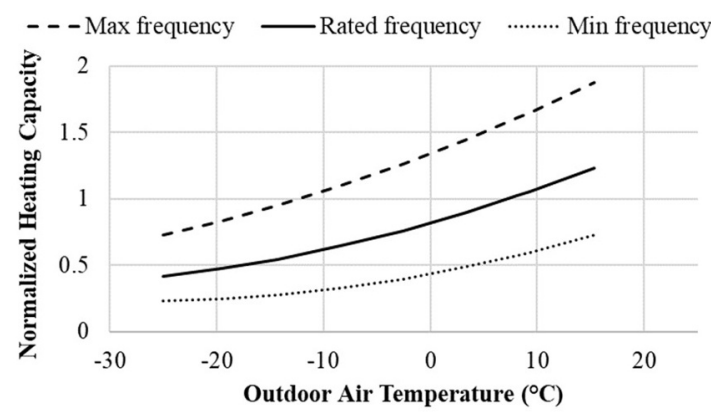

a) Unit 1

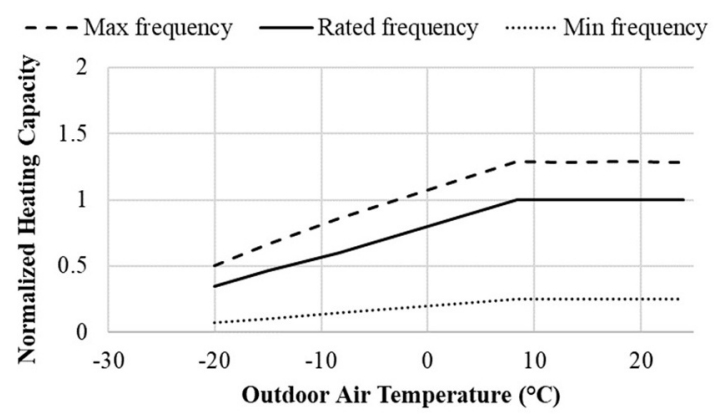

b) Unit 2

Figure 3. Normalized VCHP heating capacity curves.

Figure 4 shows the PLF as a function of PLR for both units. The curves presented in each of the graphs in this figure were developed from the performance data of each of the units [14]; [6]. The part-load performance of Unit 1 tends to vary more with respect to outdoor air temperature, with maximum PLF at a PLR of around $50 \%$. On the other hand, the steady-state efficiency of Unit 2 increases as the PLR decreases, and Unit 2 shows greater variation in capacity (i.e., lower minimum PLR).

\subsubsection{Heat Pump Control and Modulation}

In the current study, the modulation ratio corresponds to the ratio of the minimum to the maximum compressor frequencies. In the simulation models, the heat pump is controlled via a PID controller, whose signal corresponds to the compressor frequency. Setting a minimum modulation ratio thus essentially sets a minimum operating frequency for the heat pump. However, this minimum frequency should not be confused with the minimum PLR, which itself is based on capacity. To provide a better understanding of the differences between these two parameters, the minimum PLR associated with each modulation ratio is provided in Table 4.

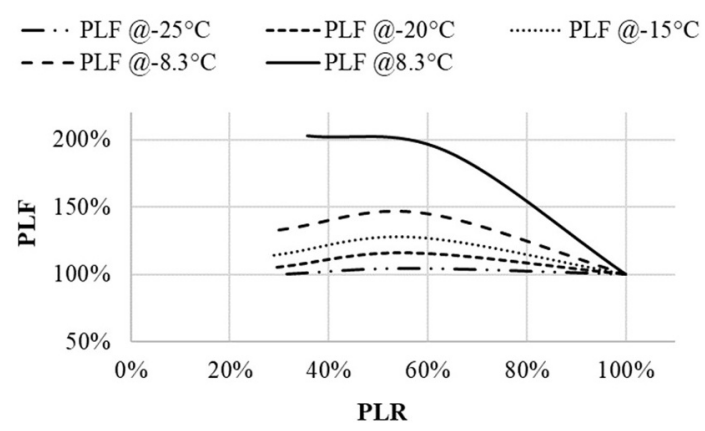

a) Unit 1

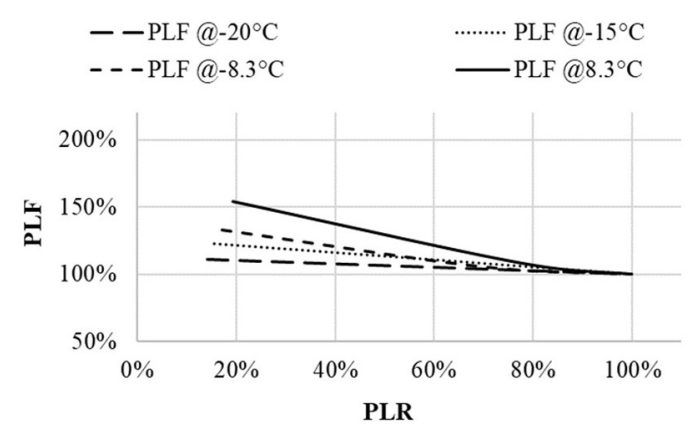

b) Unit 2

Figure 4. Part-load performance curves.

Table 4. Average minimum part-load ratios associated with each modulation ratio.

\begin{tabular}{c|ccc|ccc}
\hline & \multicolumn{3}{|c|}{ Unit 1 } & \multicolumn{3}{c}{ Unit 2 } \\
\hline Modulation ratio & $30 \%$ & $50 \%$ & $80 \%$ & $30 \%$ & $50 \%$ & $80 \%$ \\
\hline PLR & 0.39 & 0.66 & 0.91 & 0.27 & 0.76 & 0.91 \\
\hline
\end{tabular}

\section{Results}

To assess the impact of varying the modulation ratio and the sizing factor on annual energy use of the two VCHP units considered in this paper, annual system simulations were performed in TRNSYS v.18 using the appropriate CWEC weather file, with a 2.5 -minute time step to more accurately represent system controls.

\subsection{Annual Energy Performance of Unit 1}

Table 5 summarizes energy performance and operational data, such as the number of operating hours and on/off cycles in heating, for models using Unit 1. In general, all heat pump systems offer substantial reduction in heating energy use compared to the base case scenario, regardless of the Sizing Option or the minimum modulation ratio applied.

Examining the system performance of models using Unit 1 more carefully, lower modulation ratios (wider capacity modulation range) tend to be associated with higher energy savings. Primarily, this can be attributed to the fact that units tend to experience improved efficiencies at lower compressor frequencies, as observed in Figure 4. Lower minimum modulation ratios allow the unit to more fully take advantage of this 
part load performance benefit. Higher minimum modulation ratios also limit the ability of the heat pump to vary its heating output to efficiently meet building loads. This in turn increases the number of on/off cycles, reducing effective operating COPs.

Figure 5 presents the average operating COP for Unit 1 under Sizing Option 2, for all three modulation ratios (MR) investigated. The difference in COP between the modulation ratios is more noticeable at warmer outdoor temperatures. This is explained by the fact that building heating loads are reduced at milder temperatures, requiring the heat pump to operate at lower PLR. However, by imposing high modulation ratios $(50 \%$ and $80 \%)$, the heat pump units are forced to operate at PLR higher than optimal, which may result in lower efficiency (PLF). In addition, the units with higher minimum modulation ratios are to cycle significantly more, degrading operating COPs. In fact, the number of on/off cycles in heating mode is 2.5 times higher for $\mathrm{MR}=80 \%$ compared to $\mathrm{MR}=30 \%$ for Unit 1 under Sizing Option 2.

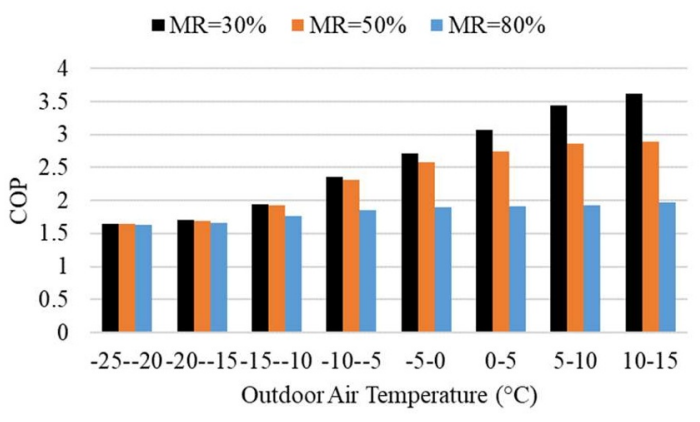

Figure 5. Operating COPs for Unit 1, Sizing Option 2.

Table 5. Annual energy performance and operating data with Unit 1 for the different Sizing Options and Modulation Ratios.

\begin{tabular}{|c|c|c|c|c|c|c|c|c|c|c|c|c|c|}
\hline \multirow{3}{*}{ End Use } & \multirow{3}{*}{ Base Case } & \multicolumn{3}{|c|}{ Sizing Option 1} & \multicolumn{3}{|c|}{ Sizing Option 2} & \multicolumn{3}{|c|}{ Sizing Option 3} & \multicolumn{3}{|c|}{ Sizing Option 4} \\
\hline & & \multicolumn{3}{|c|}{ Modulation Ratio } & \multicolumn{3}{|c|}{ Modulation Ratio } & \multicolumn{3}{|c|}{ Modulation Ratio } & \multicolumn{3}{|c|}{ Modulation Ratio } \\
\hline & & $30 \%$ & $50 \%$ & $80 \%$ & $30 \%$ & $50 \%$ & $80 \%$ & $30 \%$ & $50 \%$ & $80 \%$ & $30 \%$ & $50 \%$ & $80 \%$ \\
\hline Total heating (kWh) & 23,690 & 16,250 & 16,350 & 16,920 & 14,860 & 15,070 & 16,340 & 15,270 & 15,550 & 16,940 & 16,340 & 16,480 & 17,660 \\
\hline VCHP & - & 6,940 & 6,980 & 7,480 & 7,790 & 7,900 & 9,110 & 8,330 & 8,540 & 9,920 & 9,230 & 9,400 & 10,650 \\
\hline Elec. $B B\left(1^{\text {st }} \& 2^{\text {nd }}\right)$ & 17,990 & 3,430 & 3,490 & 3,550 & 1,230 & 1,330 & 1,380 & 1,110 & 1,160 & 1,180 & 1,260 & 1,230 & 1,190 \\
\hline$\overline{S C O P}$ & 1.00 & 1.66 & 1.64 & 1.55 & 1.98 & 1.92 & 1.68 & 1.92 & 1.85 & 1.61 & 1.73 & 1.70 & 1.52 \\
\hline $\begin{array}{l}\% \text { heat load met by } \\
\text { VCHP }\left(1^{\text {st }} \& 2^{\text {nd }}\right)\end{array}$ & - & $80 \%$ & $80 \%$ & $79 \%$ & $93 \%$ & $92 \%$ & $92 \%$ & $94 \%$ & $93 \%$ & $93 \%$ & $93 \%$ & $93 \%$ & $93 \%$ \\
\hline Heating op. hours* & - & 3,700 & 3,390 & 3,110 & 3,060 & 2,480 & 2,090 & 2,480 & 1,870 & 1,520 & 1,970 & 1,460 & 1,180 \\
\hline Heating on/off cycles & - & 550 & 1,110 & 1,690 & 2,000 & 3,660 & 4,920 & 4,090 & 6,190 & 7,320 & 6,400 & 8,070 & 8,570 \\
\hline
\end{tabular}

*Excluding defrost

Table 6. Annual energy performance and operating data with Unit 2 for the different Sizing Options and Modulation Ratios.

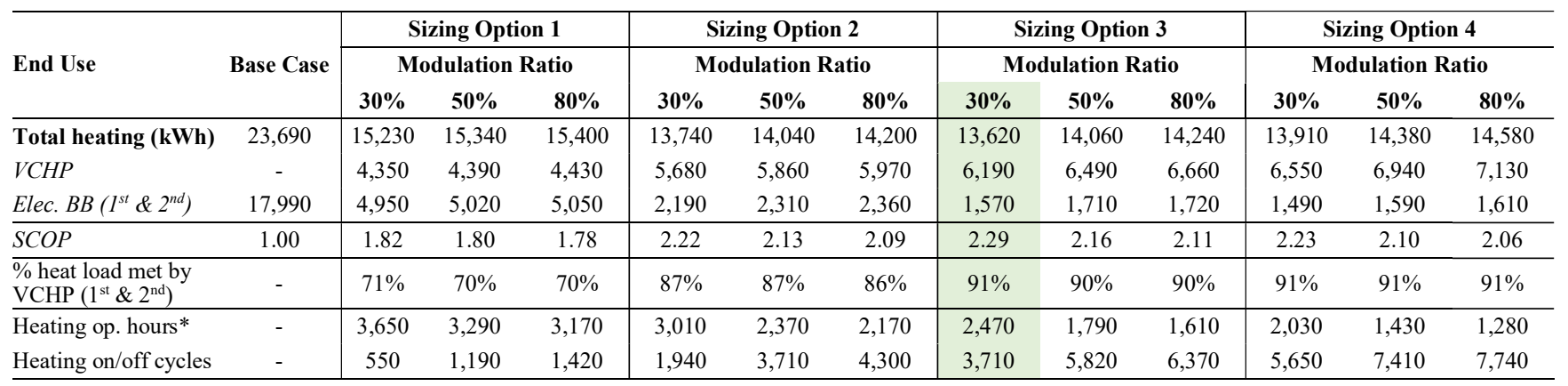

*Excluding defrost

\subsection{Annual Energy Performance of Unit 2}

Table 6 summarizes the energy performance of each option using Unit 2. Similar to results for Unit 1, high modulation ratios increase the heating energy consumption as it causes the heat pump to operate at a higher PLR and to cycle more frequently. Also, similar to findings described in the previous subsection, the larger the heat pump unit is, the lower the operating COPs are throughout the year, due to frequent on/off cycling. Appropriate sizing is also important to optimize the integration of Unit 2 due to its individual performance characteristics. Since Unit 2 experiences a more significant reduction in heating capacity at colder ambient temperatures, a degree of oversizing may be beneficial vs. the results for Unit 1. The increased heating capacity in Sizing Option 3 allows the heat pump to displace a more significant portion of auxiliary baseboard heating, greatly reducing total annual heating energy use. Sizing Option 3 can meet a larger portion of the heating load than Sizing Option 2, which allows to reduce the consumption of the auxiliary heating by nearly $30 \%$. Despite the fact that the heat pump cycles almost twice as much with Sizing Option 3 compared to Sizing Option 2, this does not increase the power consumption of the heat pump enough to cancel the 
additional savings achieved from reducing auxiliary heating. However, further oversizing beyond this point (i.e., Sizing Option 4) actually increases heating energy use, as the heat pump is unable to offer substantial reductions in auxiliary energy use (VCHP unit provides the same amount of heating as Sizing Option 3) while also cycling more frequently. This is particularly interesting in the context of the part-load performance shown in Figure 4, which shows a significant increase in COPs at lower PLRs. Such performance would suggest a benefit to maximizing the size of the unit. The simulations show that the effective COPs (i.e., when including effects for cycling) only increase for very cold temperatures $\left(-20^{\circ} \mathrm{C}\right.$ to $\left.-10^{\circ} \mathrm{C}\right)$, which represents only a small number of operating hours in the year. However, for higher temperatures, effective COPs are actually much lower due to the performance implications of more frequent cycling, limiting overall heat pump performance.

\subsection{Comparing Performance of Unit 1 vs Unit 2}

Maximum heating energy savings offered by Unit 2 are more significant than with the Unit 1 despite the fact that auxiliary energy use is higher for all Sizing Options. This can be attributed to the higher operating COPs of Unit 2 compared to Unit 1, as observed in Figure 6. In fact, despite Unit 1 reaching higher values of PLF than Unit 2, maximum operating COPs are lower for the former (see Table 3). Although the cut-off temperature for Unit 1 is lower than for Unit 2 and allows it to operate below outdoor temperatures of $-20^{\circ} \mathrm{C}$, this only represents a very small number of operating hours during the year (around 3\%). Thus, it does not generate a reduction in auxiliary energy use large enough to compensate for the reduced COP of Unit 1.

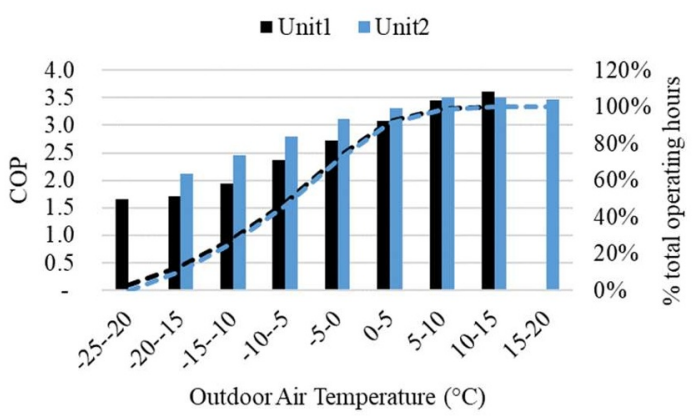

Figure 6. Operating COPs of the Units 1 and 2 for the Sizing Option 2 and $\mathrm{MR}=30 \%$.

\subsection{Discussion}

Annual energy performance of heat pumps is influenced by various factors such as the individual performance characteristics of the heat pump (part-load performance and cold-climate capacity), the modulation ratio and the size selected to meet the heating loads of the building in which it is integrated. Through a comparison of two different VCHP units and the variation of their sizes and modulation ratios, this simulation-based study highlights the following findings.
System sizing is often a challenge for heat pump systems in Canada. Units are often sized according to the cooling loads of the home, limiting energy savings benefits in heating mode. These results suggest that, for optimal heating performance, sizing systems for $17^{\circ} \mathrm{F}$ represents a good first approximation for system selection. For systems that maintain strong cold climate capacity, oversizing beyond this target capacity should be avoided. However, for units with larger capacity degradations at colder outdoor temperatures, a limited degree of oversizing may be beneficial

As demonstrated previously, the most appropriate sizing option for Unit 1, whose capacity maintenance at colder temperatures is high, is the one sized to meet $100 \%$ of the target heating load at $17^{\circ} \mathrm{F}\left(-8.3^{\circ} \mathrm{C}\right)$ at maximum capacity (Sizing Option 2). The sizing option achieving the highest reductions in annual energy use with Unit 2 is the one that meets $150 \%$ of the building load at $17^{\circ} \mathrm{F}\left(-8.3^{\circ} \mathrm{C}\right)$. In this particular case, oversizing is beneficial only because it helps overcome the strong capacity degradation at low ambient temperatures by allowing the heat pump to take on a greater portion of the heating load (and, in doing so, reduce auxiliary energy use). As shown in the two results tables above, increasing the size of the unit ceases to be beneficial as soon as the percentage of heating load covered by VCHP plateaus.

Furthermore, despite the theoretical benefits of oversizing due to improved PLFs at low PLRs, results in both Table 5 and Table 6 suggest that the more frequent cycling of larger VCHP units greatly reduces their effective operating COPs. It is worth noting that not only the number of on/off cycles increases, but total operating hours also decrease. This means that cycles are not only more frequent, but also shorter for larger units. Given that at the start of each cycle, the heat pump operates at maximum frequency (i.e., maximum PLR, and therefore lower PLF), the more frequent and shorter these cycles are, the greater the decrease of the average COPs over these cycles. This leads to the conclusion that oversized units, by cycling more and more to meet the lower heating loads, operate more often at high PLR, which considerably affects their operating COPs. Note that benefits of improving PLF with oversized units only occur at colder temperatures, which only corresponds to a low number of operating hours over the year and, thus, do not overcome the negative performance implications of more cycling. In addition, oversized units, operating for less time in heating mode, are more likely to operate more often in standby mode, which consumes power inefficiently. Note that VCHP part load performance depends greatly on the heating load profile of the building, and on the outdoor conditions. Although this study focuses only on the Montreal region, future work will examine other archetype homes, constructions and regions to better capture these impacts on the partial load behaviour of VCHP unit and its sizing.

Finally, units with lower modulating ratios are preferred because they can better adapt to the needs of the building while minimizing cycling. In addition, this allows the heat pump to operate at lower PLRs, which improves PLFs and ensures that heating loads are met 
more efficiently. This also likely results in improved thermal comfort due to smaller fluctuations in indoor temperatures.

\subsection{Modelling limitations}

In this study, minimum compressor on- or off-time is not considered in the VCHP unit modelling. As noted in Clauß et al, these constraints may change the number of on/off cycles, and impact energy flexibility metrics (which are beyond the scope of this work) [16]. This analysis represents a conservative estimate with no control limits on cycling. Future work will incorporate these features into the developed heat pump model.

\section{Conclusion}

This paper presents a simulation-based assessment of various impact factors, including specific part-load performance characteristics, sizing approaches and modulation ratios, on the annual heating energy performance of cold-climate variable-capacity heat pumps. A detailed model of a single-family housing was first developed in the Canadian city of Montreal, based on typical regional construction parameters. Using an improved VCHP model that better captures the impacts of key behaviours (cycling, defrost), two different heat pump units with specific performance characteristics, sized according to four different methods and integrated with three different modulation ratios, were then examined. Results demonstrate the strong energy savings potential of heat pumps, and the performance pitfalls of oversizing and of poorer modulating capabilities. For both VCHP units considered, high minimum modulation ratios showed reduced energy performance, driven by reduced operating COPs caused by more frequent cycling. Regarding sizing approaches, the results indicated that oversized heat pumps also exhibit reduced energy performance caused by frequent on/off cycling, which impairs operating COPs too. However, in some particular cases, when the heat pump capacity deteriorates considerably at low outdoor temperatures, it may be beneficial to slightly oversize the unit to displace a more significant portion of auxiliary heating energy use. Comparing the two VCHP units, results showed that individual performance characteristics have a great influence on the annual energy consumption as well as on the optimal sizing of the heat pump system.

The current study represents an initial analysis regarding the energy performance impacts of heat pump individual performance characteristics, sizing and modulation ratio. Future work will explore the economic aspect of the impact of proper sizing and of wide capacity modulation range, and study in detail the general cycling behaviour of the heat pump during operation.

\section{References}

[1] Natural Resources Canada (NRCan), "Comprehensive Energy Use," Office of Energy Efficiency, Ottawa (CA), 2020.

[2] J. Sager, T. Mackintosh, G. St-Onge, E. Mcdonald and M. Kegel, "Detailed Performance Assesment of Variable Capaicty inverter Driven Cold Climate Air Source Heat Pumps: Sustainable Buildings in Cold Climates," CanmetEnergy, Ottawa (CA), Varennes (CA), 2018.

[3] B. Filliard, A. Guiavarch and B. Peuportier, "Performance Evaluation Of An Air-To-Air Heat Pump Coupled With Temperate Air-Sources Integrated Into A Dwelling," in IBPSA Conference, Glasgow, Scotland, 2009.

[4] C. Wemhoener, S. Buesser and L. Rominger, "Design and integration of heat pumps for nZEB in IEA HPT Annex 49," E3S Web of Conference, vol. 111, no. 04007, 2019.

[5] Natural Resources Canada (NRCan), "Sizing and Selection Guide,” NRCan, Ottawa (CA), 2020.

[6] Northeast Energy Efficiency Partnerships (NEEP), "NEEP'S Cold Climate Air Source Heat Pump List," 2021. [Online]. Available: https://ashp.neep.org/\#!/product_list/. [Accessed December 2020].

[7] Solar Energy Laboratory, TRNSYS, a Transient SImulation Program, Madison: University of Wisconsin-Madison, 1975.

[8] M. Swinton, E. Entchev, F. Szadkowski and R. Marchand, "Benchmarking twin houses and assesment of the energy performance of two gas combo heating systems," Canadian Centre for Housing Technology (CCHT), Ottawa (CA), 2003.

[9] L. Swan, V. Ugursal and I. Beausoleil-Morrison, "A database of house descriptions representative of the Canadian housing stock for coupling to building energy performance simulation," Journal of Building Performance Simulation, vol. 2, pp. 75-84, 2009.

[10] M. M. Armstrong, M. C. Swinton, H. Ribberink, I. Beausoleil-Morrison and J. Millette, "Synthetically derived profiles for representing occupant-driven electric loads in Canadian Housing," Journal of Building Performance Simulation, vol. 2, no. 1, pp. 15-30, 2009.

[11] Canada Energy Regulator (CER), "Market Snapshot: Steady growth for heat pump technology," Govt. of Canada, Ottawa (CA), 2018.

[12] S. Prud'homme, S. Breton, J. Tamasauskas, J. Sager and M. Kegel, "A Simulation-Based Exploration of Air-Source Heat Pump Sizing in 
Canada," Natural Resources Canada (NRCan), Ottawa (CA), 2020.

[13] S. Breton, J. Tamasauskas and M. Kegel, "Evaluation of Cold Climate Variable Capacity Air-Source Heat Pumps in Canadian Residential Buildings Using an Enhanced Component Model," in 16th International Conference of IBPSA, Rome, 2019.

[14] G. St-Onge, "Variable Capacity Mini-Split Air Source Heat Pump Model for TRNSYS," École Polytechnqiue de Montréal, Montréal (CA), 2018.

[15] C. Booten, C. Christensen and J. Winkler, "Energy Impacts of Oversized Residential Air Conditioners - Simulation Study of Retrofit Sequence Impacts," National Renewable Energy Laboratory (NREL), Ottawa, 2014.

[16] J. Clauß and L. Georges, "Model complexity of heat pump systems to investigate the building energy flexibility and guidelines for model implementation," Elsevier, vol. 255, no. 03062619, 2019. 